\title{
Uso de fibrina rica em plaqueta em enxerto ósseo e implantes dentários
}

\author{
Use of platelet-rich fibrina in boné grafts and dental implants \\ Uso de fibrina rica em plaquetas en injerto de hueso e implantes dentales
}

Recebido: 20/01/2021 | Revisado: 23/01/2021 | Aceito: 25/01/2021 | Publicado: 31/01/2021

\author{
Ricardo Kerhwald \\ ORCID: https://orcid.org/0000-0002-8024-3250 \\ Centro Universitário Ingá, Brasil \\ E-mail: kerhwaldricardo@homail.com \\ Vinícius Gustavo Petronilho \\ ORCID https://orcid.org/0000-0003-0487-703X \\ Centro Universitário Ingá, Brasil \\ E-mailviniciu5@hotmail.com \\ Hebert Sampaio de Castro \\ ORCID: https://orcid.org/0000-0001-8405-357X \\ Centro Universitário Ingá, Brasi \\ E-mail: hebertash@hotmail.com \\ Fernada Ferruzzi Lima \\ ORCID: https://orcid.org/ 0000-0003-0212-7067 \\ Centro Universitário Ingá, Brasil \\ E-mail: prof.fernandalima@uninga.edu.br \\ Vilmar Divanir Gottardo \\ ORCID: https://orcid.org/0000-0001-6219-5403 \\ Centro Universitário Ingá, Brasil \\ E-mail: prof.vilmargottardo@gmail.com \\ Polyane Mazucatto Queiroz \\ ORCID: https://orcid.org/0000-0001-7324-7838 \\ Centro Universitário Ingá, Brasil \\ E-mail: prof.polyanequeiroz@uninga.edu.br
}

\section{Resumo}

Fibrina rica em plaquetas (PRF, do inglês platelet-rich fibrin) é um concentrado de sanguíneo produzido de forma totalmente natural, sem a utilização de anticoagulante. Esse concentrado é aplicado com o objetivo de promover a aceleração na cicatrização de tecidos moles e duros. Na odontologia, esse biomaterial vem sendo utilizado em vários procedimentos. O presente trabalho foi desenvolvido com o objetivo descrever um caso clínico em que foram utilizadas membranas PRF e PRF líquida associadas a osso bovino liofilizado no tratamento de paciente com maxila atrófica para viabilizar instalação de implantes e reabilitação protética. Diante dos resultados do caso clínico apresentado, pode-se concluir que o uso de PRF apresenta resultado favorável na regeneração de tecidos ósseos e gengivais. Quando associado a material para enxerto atua acelerando o processo de cicatrização além de auxiliar na maturação do enxerto promovendo um aumento do volume ósseo favorecendo a instalação de implantes e reabilitação protética.

Palavras-chave: Cicatrização; Implante dentário; Materiais biocompatíveis; Plasma rico em plaquetas; Regeneração tecidual.

\begin{abstract}
Platelet-rich fibrin (PRF) is a blood concentrate produced in a totally natural way, without the use of anticoagulants. This concentrate is applied with the objective of promoting acceleration in the healing of soft and hard tissues. In dentistry, this biomaterial has been used in several procedures. The present work was developed with the objective of describing a clinical case in which PRF and liquid PRF membranes associated with lyophilized bovine bone were used in the treatment of a patient with atrophic maxilla to enable implant installation and prosthetic rehabilitation. Given the results of the clinical case presented, it can be concluded that the use of PRF has a favorable result in the regeneration of bone and gingival tissues. When associated with graft material, it accelerates the healing process, in addition to assisting in the maturation of the graft, promoting an increase in bone volume, favoring the installation of implants and prosthetic rehabilitation.
\end{abstract}

Keywords: Biocompatible materials; Dental implantes; Platelet-rich plasma; Tissue regeneration; Wound healing.

\section{Resumen}

La fibrina rica en plaquetas (PRF, de inglés platelet-rich fibrin) es un concentrado de sangre producido de forma totalmente natural, sin el uso de anticoagulantes. Este concentrado se aplica con el objetivo de promover la 
aceleración en la cicatrización de tejidos blandos y duros. En odontología, este biomaterial se ha utilizado en varios procedimientos. El presente trabajo se desarrolló con el objetivo de describir un caso clínico en el que se utilizaron PRF y membranas de PRF líquidas asociadas a hueso bovino liofilizado en el tratamiento de un paciente con maxilar atrófico para permitir la instalación de implantes y rehabilitación protésica. Dados los resultados del caso clínico presentado, se puede concluir que el uso de PRF tiene un resultado favorable en la regeneración de tejidos óseos y gingivales. Cuando se asocia con material de injerto, acelera el proceso de cicatrización, además de ayudar a la maduración del injerto, promoviendo un aumento del volumen óseo, favoreciendo la instalación de implantes y la rehabilitación protésica.

Palabras clave: Cicatrización de heridas; Implantes dentales; Materiales biocompatibles; Plasma rico en plaquetas; Regeneración tisular.

\section{Introdução}

Atualmente, a utilização dos agregados plaquetários autólogos é uma realidade inovadora nos procedimentos médicos e odontológicos com o objetivo de promover uma melhor cicatrização dos tecidos moles e duros (Feigin \& Shope, 2019; Fan, Perez \& Dym, 2020; Xu et al, 2020). Dentre os agregados, a Fibrina Rica em Plaquetas (PRF, do inglês platelet-rich fibrin) tem sido frequentemente empregada em procedimentos regenerativos pois os grânulos de plaquetas, presente em alta concentração, apresentam grande quantidade de citocinas e fatores de crescimento (Xu et al, 2020).

Estes concentrados plaquetários propõem uma aceleração na cicatrização de tecidos moles e duros através do aumento da concentração de fatores de crescimento, como o fator de crescimento transformante-b (TGF-b), fator de crescimento semelhante à insulina1 (IGF-1), fator de crescimento derivado das plaquetas (PDGF), fator de crescimento vascular endotelial (VEGF), fator de crescimento fibroblástico (FGF), fator de crescimento epidermal (EGF) e fator de crescimento epidermal derivado de plaquetas (PDEGF), metaloproteinases e interleucinas. Desse modo, observa-se uma proliferação e diferenciação osteogênica auxiliando no processo de regeneração tecidual (Andia \& Abate, 2013; Rodriguez et al, 2014; Mourão et al, 2015; Fan, Perez \& Dym, 2020; Strauss et al, 2020).

A obtenção do concentrado é feita por meio da amostra de sangue do próprio paciente, sem anticoagulante, para ser centrifugado instantaneamente (Otárola et al, 2016). O tempo e velocidade de centrifugação devem ser determinados de acordo com às características desejadas para o concentrado sanguíneo (Piao, Park \& Jo, 2017; Croisé et al, 2019). Diferentes formas de PRF podem ser utilizadas, de acordo com a demanda, podendo ser utilizada na forma de membrana de PRF, em forma de plug de PRF ou ainda na forma líquida (Choukroun et al, 2006). A PRF tem sido utilizada em diferentes procedimentos cirúrgicos, como aumento do assoalho sinusal, tratamento da recessão gengival, defeitos de furca, reabilitação maxilar antes da colocação do implante, restauração de defeitos peri-implantares, cicatrização dos alvéolos de extração e defeitos intra-ósseos, apresentando resultados promissores (Sezgin et al, 2017; Fan, Perez \& Dym, 2020; Strauss et al, 2020). O presente trabalho foi desenvolvido com o objetivo de descrever um caso clínico de tratamento de maxila atrófica em que foi empregado diferentes tipos de PRF associados, sendo utilizado a PRF líquida associada a osso bovino liofilizado, formando o Stick Bone, e o mesmo foi protegido para cicatrização com uma membrana de PRF.

\section{Metodologia e Relato de Caso}

O presente artigo trata-se de um estudo de caso descritivo de um caso clínico retroativo (Pereira et al,2018). Esse estudo foi realizado após a aprovação do Comitê de Ética em Pesquisa local, via Plataforma Brasil (CAAE: 29185020.7.0000.5220).

Paciente do sexo masculino, 66 anos, leucoderma, apresentou-se à clínica com queixa de ausência dos elementos superiores e com a expectativa de reabilitação da região edêntula. Ao exame clínico (Figura 1A), diagnosticou-se, em maxila, a ausência dos elementos 13 ao 25. Em exame complementar, por meio da radiografia panorâmica (Figura 1B), foi observada altura óssea limítrofe em relação ao seio maxilar na região dos dentes 24 e 25, ausentes. 
Figura 1 - Aspecto clínico (A) e Radiografia panorâmica iniciais (B).

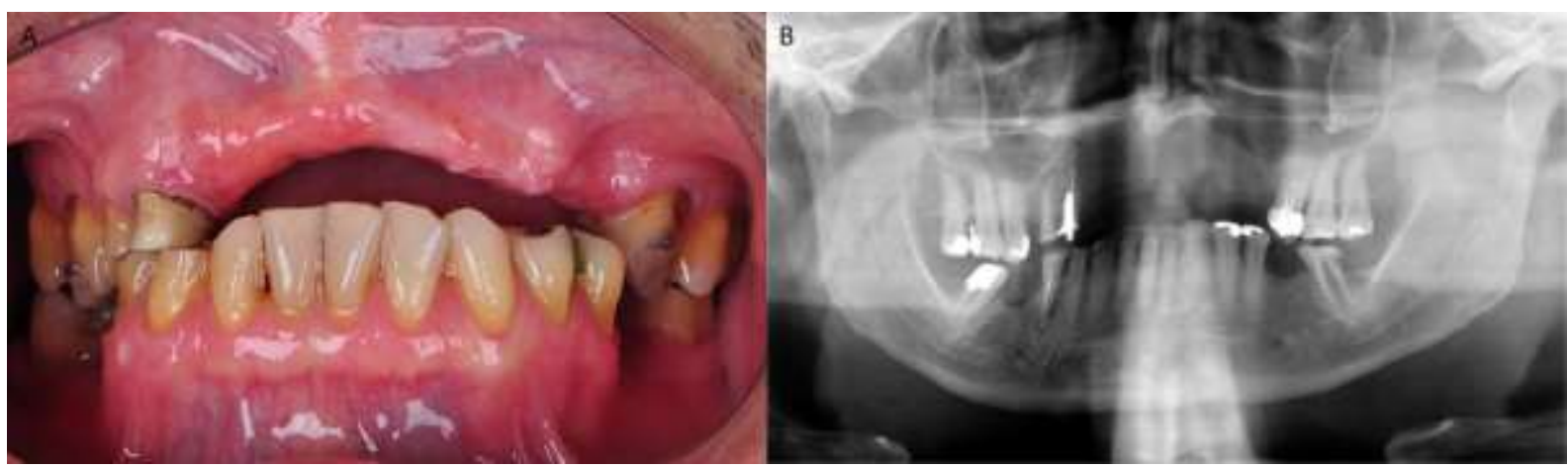

Fonte: Autores.

$\mathrm{Na}$ foto clínica, observa-se o aspecto de atrofia sugestivo de pouca espessura de tecido ósseo, da região dos dentes 14 ao dente 25. Na radiografia panorâmica é possível observar a reabsorção alveolar na região referida a extensão do seio maxilar do lado esquerdo.

Foi planejado levantamento de seio maxilar do lado esquerdo, na região dos dentes 24 e 25 e regeneração óssea em espessura em toda região edêntula com posterior instalação de implantes dentários na região dos dentes 12, 22, 24 e 25 para futura reabilitação protética.

No ato cirúrgico, foi realizada osteotomia (Figura 2) para acesso à membrana de Schneider do seio maxilar do lado esquerdo, na região dos elementos 24 e 25; e com broca lança foram confeccionados, na tábua óssea vestibular, pontos de nutrição sanguínea para o enxerto ósseo.

Figura 2 - Área de osteotomia na região dos dentes 24 e 25 para realizar levantamento da membrana do seio maxilar do lado esquerdo.

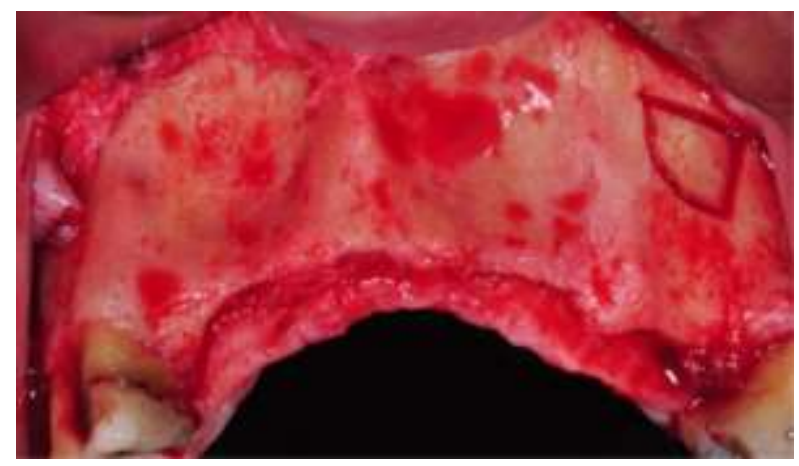

Fonte: Autores.

Observe o tecido ósseo na região, durante o transoperatório. Na região do dente 25 é possível observar a área de osteotomia para posterior colocação de enxerto ósseo.

Foi realizada a flebotomia e então foram coletados seis tubos de sangue do próprio paciente para centrifugação em 2700 rpm durante 12 minutos para obtenção de coágulos de L-PRF para confecção da membrana de PRF. Esse processo foi realizado na centrífuga Intra Spin L-PRF (Intra-Lock®, Boca-Raton, USA). Posteriormente, foram coletados mais dois tubos com sangue e, na mesma centrífuga, esses foram centrifugados em 1300 rpm durante três minutos, para obtenção da PRF líquida (I-PRF).

A PRF líquida foi associada ao osso bovino liofilizado e a membrana de PRF (Figura 3) para confecção de uma peça de Stick Bone para regeneração óssea de levantamento de seio maxilar (região dos dentes 24 e 25). 
Figura 3 - Membrana de PRF (A). PRF líquida (B). Osso bovino liofilizado com membrana de PRF (C) e associados ao PRF líquido (D) formando o Stick Bone (E).

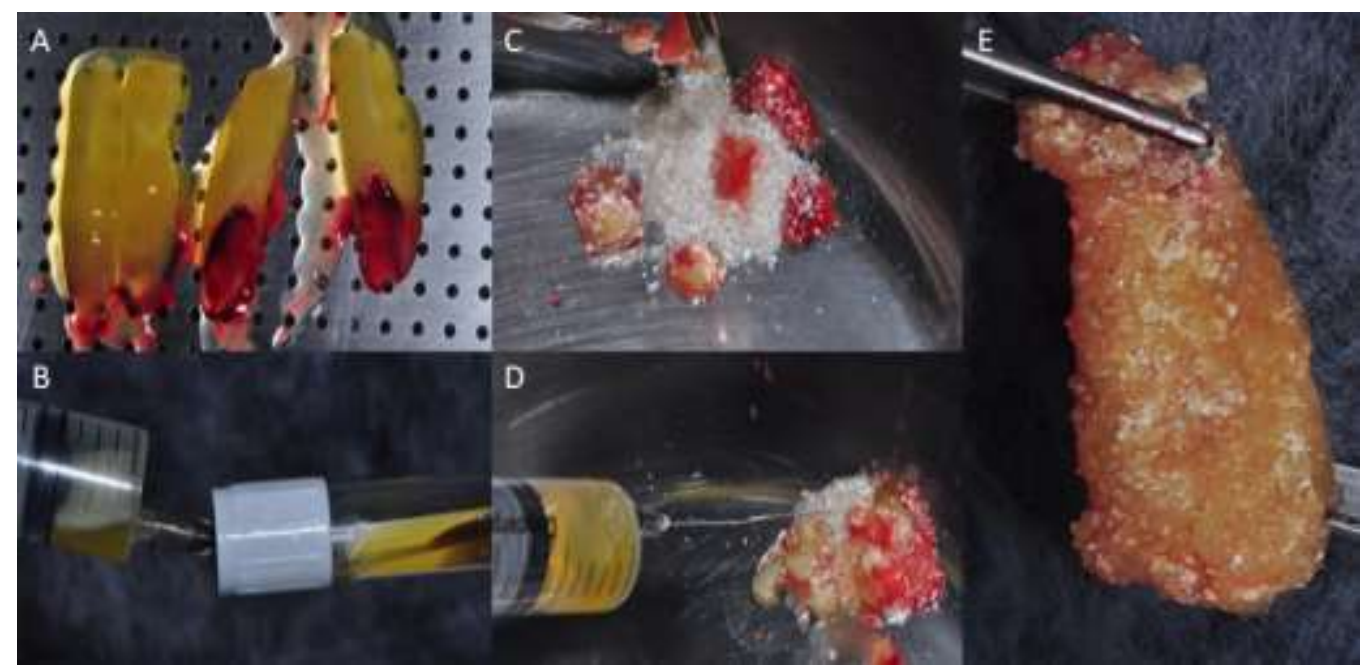

Fonte: Autores.

Na Figura 3 observa-se a membrana de PRF após a centrifugação (A). Foi realizada a aspiração da PRF líquida (B). O enxerto bovino liofilizado foi associação a membrana de PRF fragmenta (C) e posteriormente foi adicionada a PRF líquida (D) para preparação do Stick bone $(\mathrm{E})$.

A peça de Stick Bone foi dividida em duas partes. Inicialmente, uma parte da peça de Stick Bone foi colocada sob a membrana do seio maxilar para seu levantamento. No mesmo ato cirúrgico foram instalados os implantes dentários e parafusos de fixação de enxerto e a outra parte da peça do Stick Bone foi colocada sobre as roscas expostas e osso vestibular atrófico. O material para regeneração óssea foi coberto com membranas de colágeno e por membranas de PRF (Figura 4). 
Figura 4 - Instalação dos implantes (A) com stick bone recobrindo-os (B) e colocação de membrana de colágeno (C) e membrana de PRF (D) para proteger a área.

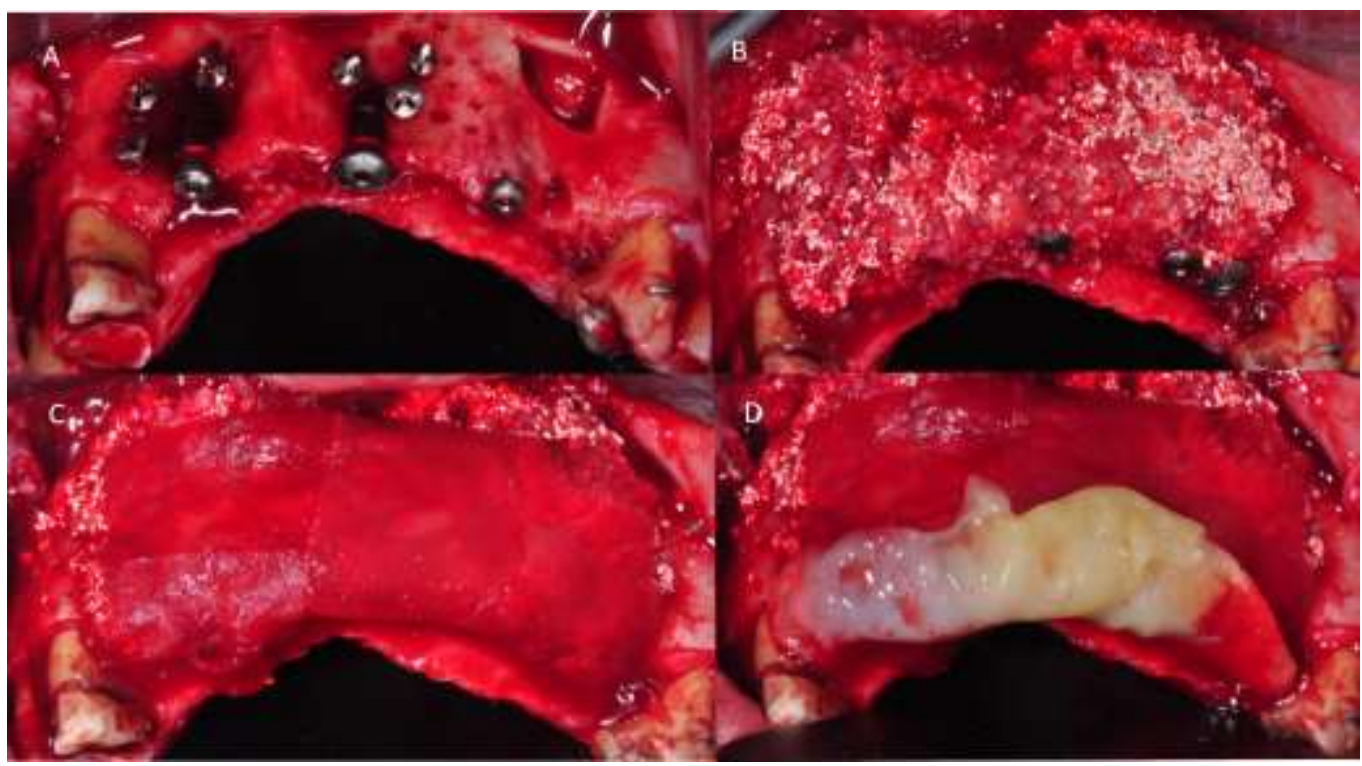

Fonte: Autores.

Observa a área com a instalação dos implantes dentários (A) em que é possível observar exposição da parte vestibular do implante. Foi colocado o Stick bone na região, recobrindo os implantes dentários (B). A proteção desse material foi realizada com a membrana de colágeno (C) e a membrana de PRF (D) na área mais externa.

Após a finalização do ato cirúrgico, foi prescrita a medicação pós-operatória com uso de amoxilina 1500mg durante 7 dias, anti-inflamatórios e, se necessário, analgésico. Para higienização local, indicou-se o uso de digluconato de clorexidina (0.2\%). O paciente foi acompanhado em 10, 14 e 45 dias. Ao avaliar o exame tomográfico, observou-se volume ósseo favorável na região vestibular da maxila e na região de seio maxilar do lado direito.

Após 8 meses foi realizada a reabertura (Figura 5) para a instalação dos cicatrizadores. Foram utilizadas oito membranas de A-PRF para otimizar a cicatrização e proteger a crista óssea que ficaria exposta.

Figura 5 - Reabertura 8 meses para instalação dos cicatrizadores.

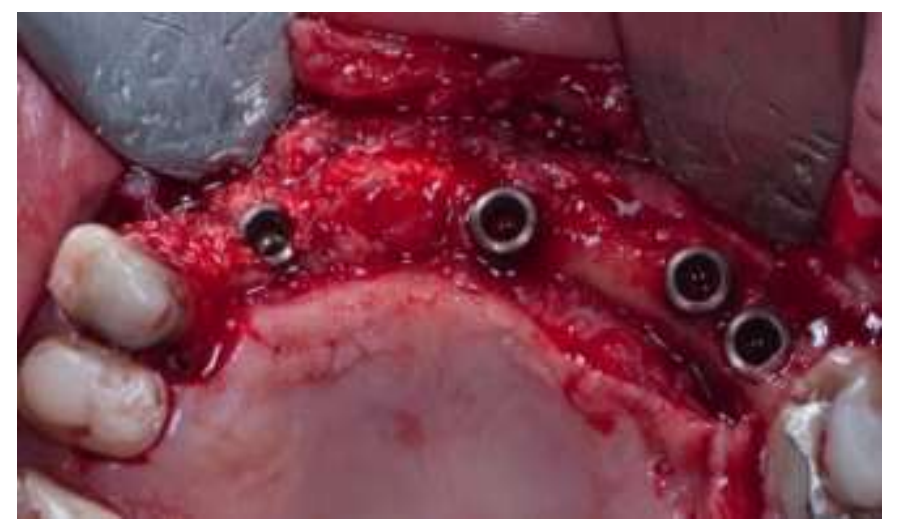

Fonte: Autores.

Observe o aspecto clínico da região na reabertura para a instalação dos cicatrizadores.

O paciente passou por reabilitação protética (Figura 6) e segue em acompanhamento de 12 meses de pós-operatório. 
Figura 6 - Aspecto clínico final após reabilitação.

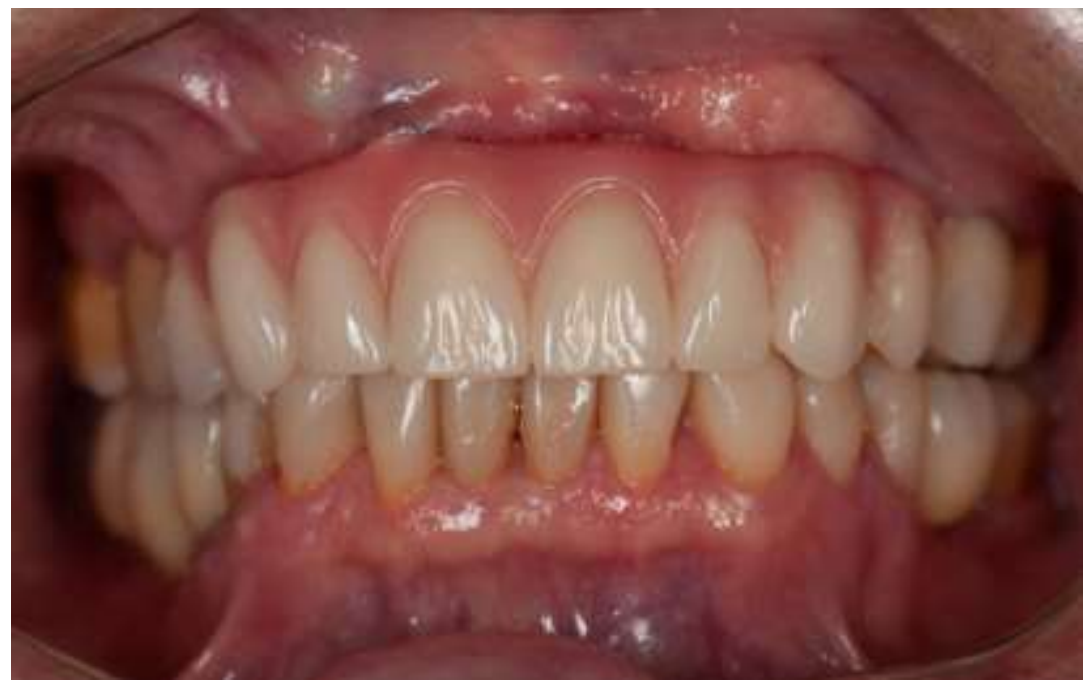

Fonte: Autores.

Observe o aspecto clínico final após a reabilitação do paciente com prótese sobre implante reestabelecendo a função e a estética do paciente.

\section{Discussão}

A PRF veio para agregar a regeneração tecidual, tornando uma cicatrização mais eficaz e qualificada, tanto óssea quanto em tecidos moles. Esse concentrado traz um novo conceito para o processo cicatricial de tecidos e tem sido amplamente utilizada na Odontologia (Temmerman et al, 2016; Castro et al, 2017) Suas plaquetas constituintes contêm um forte potencial regenerativo e, isoladas do sangue periférico, são uma fonte de fatores de crescimento com capacidade de estimular a proliferação celular, a remodelação da matriz, a angiogênese e a regeneração tecidual (Choukroun et al, 2006).

A associação da PRF com enxerto ósseo liofilizado foi comparada por alguns autores. Choukroun et al (2006) avaliaram o potencial da PRF, sustância autógena, em combinação aloenxerto ósseo liofilizado concluindo que a utilização de PRF para levantamento do seio acelerou a regeneração óssea. No presente caso clínico apresentado, o osso bovino liofilizado foi associado à PRF líquida, para levantamento de seio maxilar e regeneração óssea em região edêntula maxilar. Esse material foi protegido com membrana de PRF. Assim, observou-se regeneração óssea ao redor dos implantes, potencializando a cicatrização e protegendo a crista óssea exposta.

Além do levantamento do seio maxilar, vários estudos destacam outras aplicações clínicas da PRF. No estudo de Temmerman et al (2016) a utilização de PRF como material de preenchimento do alvéolo para a preservação da crista foi benéfica, na avaliação aos três meses, quando comparada com a cicatrização natural. Além disso, foi observado menor desconforto e dor pós-operatória. Em outro estudo os resultados mostraram que o uso concomitante de PRF com enxerto ósseo liofilizado pode reduzir a 
reabsorção e acelerar a consolidação óssea durante o período pós-operatório (Pan et al, 2019). A relação do uso de PRF com melhor conforto pós-operatório é um fator importante para o bem estar do paciente e que tem um peso ainda maior se considerada a extensão da intervenção cirúrgica realizada no presente estudo.

O uso combinado de fatores de crescimento com antibióticos de amplo espectro pré e pósoperatórios em um curto período de tempo resultou em uma maior taxa de sobrevivência do implante no final do período de um ano após a instalação do implante (Medikeri et al, 2018). Neste estudo foi administrado amoxilina $(1500 \mathrm{mg})$ no primeiro dia do pré-operatório e prescrito por mais cinco dias no pós-operatório. O digluconato de clorexidina $(0,2 \%)$ também foi recomendado por mais duas a três semanas. A administração de antibióticos, além da maior taxa de sobrevida do implante, como apontado por Medikeri et al (2018), auxilia no combate a possível processo infeccioso devido a intervenção cirúrgica diminuindo a chance de proliferação de infecção. Embora a atuação da medicação é importante, é válido considerar ainda que uma melhor cicatrização também é uma forma de prevenir infecção, já que com a cicatrização tecidual o enxerto não estará exposto a possíveis contaminações (Simonpieri et al, 2012).

No caso clínico relatado por Sousa et al (2017) para tratamento da peri-implantite foi realizado o desbridamento dos implantes com acesso cirúrgico e emprego de PRF para preenchimento dos defeitos ósseos. Os resultados apresentados aos 12 meses de observação revelaram maior contato entre o osso e o implante após o tratamento das lesões com PRF. De acordo com os autores, os achados clínicos e radiográficos encontrados com o emprego de L-PRF podem ser justificados pelas propriedades apresentadas pela PRF, como citosinas, leucócitos, células mesenquimais e principalmente através de seus fatores de crescimento. Esse resultado de contato entre o osso e implante também obtido em nosso estudo é bastante relevante já que inicialmente havia exposição das espiras cervicais dos implantes dentários.

Pimentel et al. (2014) em um caso clínico, além de enxerto autógeno, utilizaram enxerto alógeno derivado de osso bovino inorgânico associado a membranas de PRF, como no presente estudo. Os autores concluíram que o uso da membrana de PRF para a resolução deste caso clínico resultou em melhora e aceleração da cicatrização da ferida cirúrgica, maior espessura gengival e auxílio na maturação do enxerto ósseo, contribuindo para o resultado estético final dos tecidos peri-implantares. Além dos benefícios biológicos, é importante considerar resultados estéticos satisfatórios, devido a expectativa dos pacientes. A PRF melhora o fechamento precoce da ferida, a maturação dos enxertos ósseos e o resultado estético final dos tecidos moles peri-implantares e periodontais (Toffler et al, 2009). Assim, podemos observar que o uso do PRF viabiliza a reabilitação, otimiza a cicatrização, minimiza os riscos de infecção e auxilia nos resultados estéticos, ou seja, atendendo todas as necessidades do paciente de modo satisfatório. 


\section{Considerações Finais}

O uso de PRF apresenta resultado favorável na regeneração de tecidos ósseos e gengivais. Quando associado a material para enxerto atua acelerando o processo de cicatrização além de auxiliar na maturação do enxerto promovendo um aumento do volume ósseo favorável favorecendo a instalação de implantes e reabilitação protética. Bons resultados clínicos podem ser observados com sua aplicação. Serão válidos estudos clínicos futuros comparando aspectos da cicatrização e reparação com e sem uso de PRF, em um mesmo paciente.

\section{Referências}

Andia, I., \& Abate, M. (2013). Platelet-rich plasma: underlying biology and clinical correlates. Regenerative medicine. 8, 645-658.

Castro, A. B., Meschi, N., Temmerman, A., Pinto, N., Lambrechts, P. \& Teughels, W. (2017). Regenerative potential of leucocyte- and platelet-rich fibrin. Part A: intra-bony defects, furcation defects and periodontal plastic surgery. A systematic review and meta-analysis. J Clin Periodontol. 44(1), 67-82.

Choukroun, J., Diss, A., Simonpieri, A., Girard, M.O., Schoeffler, C. \& Dohan, S. L. (2006). Platelet-rich fibrin (PRF): a second-generation platelet concentrate. Part V: histologic evaluations of PRF effects on bone allograft maturation in sinus lift. Oral Surg Oral Med Oral Pathol Oral Radiol Endod. 101(3), 299-303.

Croisé, B., Paré, A., Joly, A., Louisy, A., Laure, B. \& Goga, D. (2019). Optimized centrifugation preparation of the platelet rich plasma: Literature review. J Stomatol Oral Maxillofac Surg. (19), 30165-X.

Fan, Y., Perez, K. \& Dym, H. (2020). Clinical Uses of Platelet-Rich Fibrin in Oral and Maxillofacial Surgery. Dent Clin North Am. 64(2), 291-303.

Feigin, K. \& Shope, B. (2019). Use of Platelet-Rich Plasma and Platelet-Rich Fibrin in Dentistry and Oral Surgery: Introduction and Review of the Literature. J Vet Dent. 36(2), 109-123.

Medikeri, R. S., Meharwade, V., Wate, P. M. \& Lele, S. V. (2018). Effect of PRF and allograft use on immediate implants at extraction sockets with periapical infection. Bull Tokyo Dent Coll. 59(2), 97-109.

Mourão, C. F. A. B., Valiense, H., Melo, E. R., Mourão, N. B. M. F. \& Maia, M. D. C. (2015). Obtention of injectable platelets rich-fibrin (i-PRF) and its polymerization with bone graft: technical note. Rev Col. Bras Cir. 42(6), 421-423.

Otárola, W. E., Nunez, G. C., Vaz, L. G. \& Kuga, M. C. (2016). Fibrina rica en plaquetas (PRF): una alternativa terapéutica en odontologia. Rev Estomatol Herediana. 26(3), 173-178.

Pan, J., Xu, Q., Hou, J., Wu, Y., Liu, Y., Li, R., Pan, Y. \& Zhang, D. (2019). Effect of platelet-rich fibrin on alveolar ridge preservation: A systematic review. J Am Dent Assoc. 150(9), 766-778.

Pereira, A. S., Shitsuka, D. M., Parreira, F. J., \& Shitsuka, R. (2018). Metodologia da pesquisa científica. Ed. UAB/NTE/UFSM. https://repositorio.ufsm.br/bitstream/handle/1/15824/Lic_Computacao_Metodologia-Pesquisa-Cientifica.pdf?sequence=1

Piao, L., Park, H. \& Jo, C. H. (2017). Theoretical prediction and validation of cell recovery rates in preparing platelet-rich plasma through a centrifugation. PloS one. 12:e0187509.

Pimentel, W., Carrijo, R. C. \& Tiossi, R. (2014) Nova técnica L-PRF segmentada para procedimentos regenerativos e implantares. ImplantNews. 11(3), 305310.

Rodriguez, I. A., Growney-Kalaf, E. A., Bowlin, G. L. \& Sell, S. A. (2014). Platelet-rich plasma in bone regeneration: engineering the delivery for improved clinical efficacy. BioMed research international. 2014:392-398.

Sezgin, Y., Uraz, A., Taner, I. L. \& Çulhaoglu, R. (2017). Effects of platelet-rich fibrin on healing of intra-bony defects treated with anorganic bovine bone mineral. Braz Oral Res. 31(1),

Simonpieri, A., Del Corso, M., Vervelle, A., Jimbo, R., Inchingolo, F. \& Sammartino, G., (2012). Current knowledge and perspectives for the use of plateletrich plasma (PRP) and platelet-rich fibrin (PRF) in oral and maxillofacial surgery part 2: Bone graft, implant and reconstructive surgery. Curr Pharm Biotechnol. 13(7), 1231-1256.

Sousa, E. O., Botelho, A. C. L., Duarte, P.T., Sessim, C., Silva, D. G. \& Boghossian, C. M. S. (2017). Tratamento da peri-implantite com emprego de L-PRF: relato de caso clínico. Braz J Periodontol. 27(4), 91-98.

Strauss, F. J., Nasirzade, J., Kargarpoor, Z., Stähli, A. \& Gruber, R. (2020). Effect of platelet-rich fibrin on cell proliferation, migration, differentiation, inflammation, and osteoclastogenesis: a systematic review of in vitro studies. Clin Oral Investig. 24(2), 569-584.

Temmerman, A., Vandessel, J., Castro, A., Jacobs, R., Teughels, W. \& Quirynen, M. (2016). The use of leucocyte and pletelet-rich fibrin in socket management and ridge preservation: a split-mouth, randomized, controlled clinical trial. J Clin Periodontol. 43(11), 990-999. 
Research, Society and Development, v. 10, n. 1, e56510112210, 2021

(CC BY 4.0) | ISSN 2525-3409 | DOI: http://dx.doi.org/10.33448/rsd-v10i1.12210

Toffler, M., Toscano, N., Holtzclaw, D., Del Corso, M. \& Ehrenfest, D. D. (2009). Introducing Choukroun's platelet rich fibrin (PRF) to the reconstructive surgery milieu. J Implant Advanced Clin Dent. 1(6), 21-32.

Xu, J., Gou, L., Zhang, P., Li, H. \& Qiu, S. (2020). Platelet-Rich Plasma and Regenerative Dentistry. Aust Dent J. 7. 10.1111/adj.12754. 